\title{
Reassessment of the distribution and population size of Spizella wortheni
}

\author{
LAURA M. SCOTT-MORALES, PATRICIA VELA-COIFFIER, \\ MAURICIO COTERA-CORREA, MIRNA ALMEJO-RAMOS and \\ JULIO CANALES-DELGADILLO
}

\section{Summary}

Information deficit constrains our capacity to assess the status of threatened species in regional and global contexts. In this study of the endangered Worthen's Sparrow Spizella wortheni, we first review its current and potential distribution using the species distribution software, Maxent. An initial basic model was constructed using historical records, and used to guide a subsequent search for additional populations in summer 2013. Using the information gathered from our survey, we built a second, breeding model, to update the current and potential species distribution. Population size was estimated using line transects of variable length to count singing males and calculate densities per to ha. We found Io new small reproductive populations dispersed south of the established core area, increasing the extent of occurrence of the species from $25 \mathrm{~km}^{2}$ to almost $17,000 \mathrm{~km}^{2}$. Suitable habitat across the species' range was more than threefold higher in the breeding compared with the basic model. We counted 316 males, with a mean density of four individuals per to ha. Our results demonstrate that conservation assessment based on limited records can exaggerate the vulnerability of species, and confirm that the Worthen's Sparrow population and geographic distribution range are larger than previously determined, indicating that the Red List status of this species should be reconsidered. The use of niche models was successful in enhancing species information data quantity (e.g. range extensions) and quality (e.g. more precise habitat requirements), facilitating improved understanding of needs and conservation status in the wild.

\section{Introduction}

Our ability to protect species and their habitats is limited by the tremendous field effort needed to obtain key information to determine conservation status, including sufficient distribution and population size data ('Endangered' $\mathrm{A}_{2}$ and $\mathrm{B}_{1}$ and B2, IUCN 2012), in addition to financial constraints on the design of long-term species studies.

Worthen's Sparrow Spizella wortheni is an example of a species lacking adequate data to enable verification of its status in the wild. This New World sparrow of the Central Mexican Plateau is an endemic non-migrant emberizid of desert shrubland (Wege et al. 1993, Behrstock et al. 1997). The drastic reduction in its distribution range (Sada 1987, Wege et al. 1993) and reports of a small and ever decreasing population of only Ioo individuals, validate its 'Endangered' status on the IUCN Red List (Birdlife International 2016).

In Mexico, Worthen's Sparrow is classified as at risk of extinction (SEMARNAT 2010). Uncertainties regarding population size and the continuing transformation of natural vegetation into agricultural land has increased concern for this species, which for decades was thought to inhabit only a small region of the Mexican high plateau in the Chihuahuan Desert (Wege et al. 1993). However, in the last decade, the presence of Worthen's sparrow has been confirmed in the 
southernmost part of its known range (Canales del Castillo 2010, Canales-Delgadillo et al. 2010). In addition, genetic and ecological studies suggest a population highly dispersed over a wide range, which may indicate a larger population size than previously supposed (CanalesDelgadillo et al. 2012).

Our objective was to outline the actual status of Worthen's sparrow in the wild, through an intensive search for new localities, initially close to known occurrences, and subsequently across an expanded search zone. After construction of a basic model using historical records, we searched for additional populations. Using new information gathered in the summer of 2013, we constructed a breeding model to update the actual and potential distribution of the species. We also estimated population size.

\section{Methods}

\section{Model building}

\section{Filtering of input data}

Prior to modelling the geographic distribution of the species, all records were screened to remove duplicate data and reduce location error. Records were verified for geographical congruence (coordinates inside the known historical area of distribution) by overlying them with a digital layer map of Mexican states and counties (INEGI 2010a). We did not consider historical records from Chihuahua, Puebla, Veracruz and Tamaulipas in Mexico, because in previous visits to these sites we were unable to confirm the presence of Worthen's Sparrow, as the landscapes had been cleared for agriculture. A single record from Silver City, USA, considered by the AOU (1998) to be accidental, was also excluded. We applied spatial filtering using ArcGis 9.3.I (ESRI 2009) by selecting one record within each radius of $2 \mathrm{~km}$, the minimum distance acceptable to improve Moran's I index (until the spatial distribution of records was random). After data cleaning, 398 out of 446 and 296 out of 316 records remained and were used to run the basic and breeding models, respectively.

\section{Species distribution model}

We used the software Maxent (version 3.3.3e; Phillip et al. 2004, 2010) to build two models of the potential distribution of Worthen's Sparrow, the basic and the breeding models. The former was constructed using the dataset (1980-2013) of Scott-Morales and Vela-Coiffier (2015) which includes records from all seasons of the year. For the breeding model, we searched in the summer of 2013 for new populations in all predicted suitable areas (including those with low and high probability) obtained from the output map generated by the basic model. With these new records, we updated the potential distribution of the species.

\section{Construction of a biotic-abiotic mobility (BAM) scenario}

We defined our study area in accordance with the concept of BAM (Soberón and Peterson 2005; Soberón and Nakamura 2009). BAM represents the combination of the three main factors that define an area of distribution of a species: where A represents the region with abiotic conditions that are favourable to the species; $\mathrm{B}$ represents the region with biotic conditions that are favourable to the species; and $\mathrm{M}$ represents the area that has been accessible to the species over a long period of time (Brave et al. 2011). Since Worthen's Sparrow has a restricted distribution that is confined to the Mexican Plateau, we limited the study area to the 'Meseta Central Matorral' (MCM) ecoregion (Figure 1; Williams et al. 2014). This ecoregion corresponds to region M (accessible area) for this species, and includes all vegetation types known to be suitable for Worthen's Sparrow, based on observations over the last three decades. 


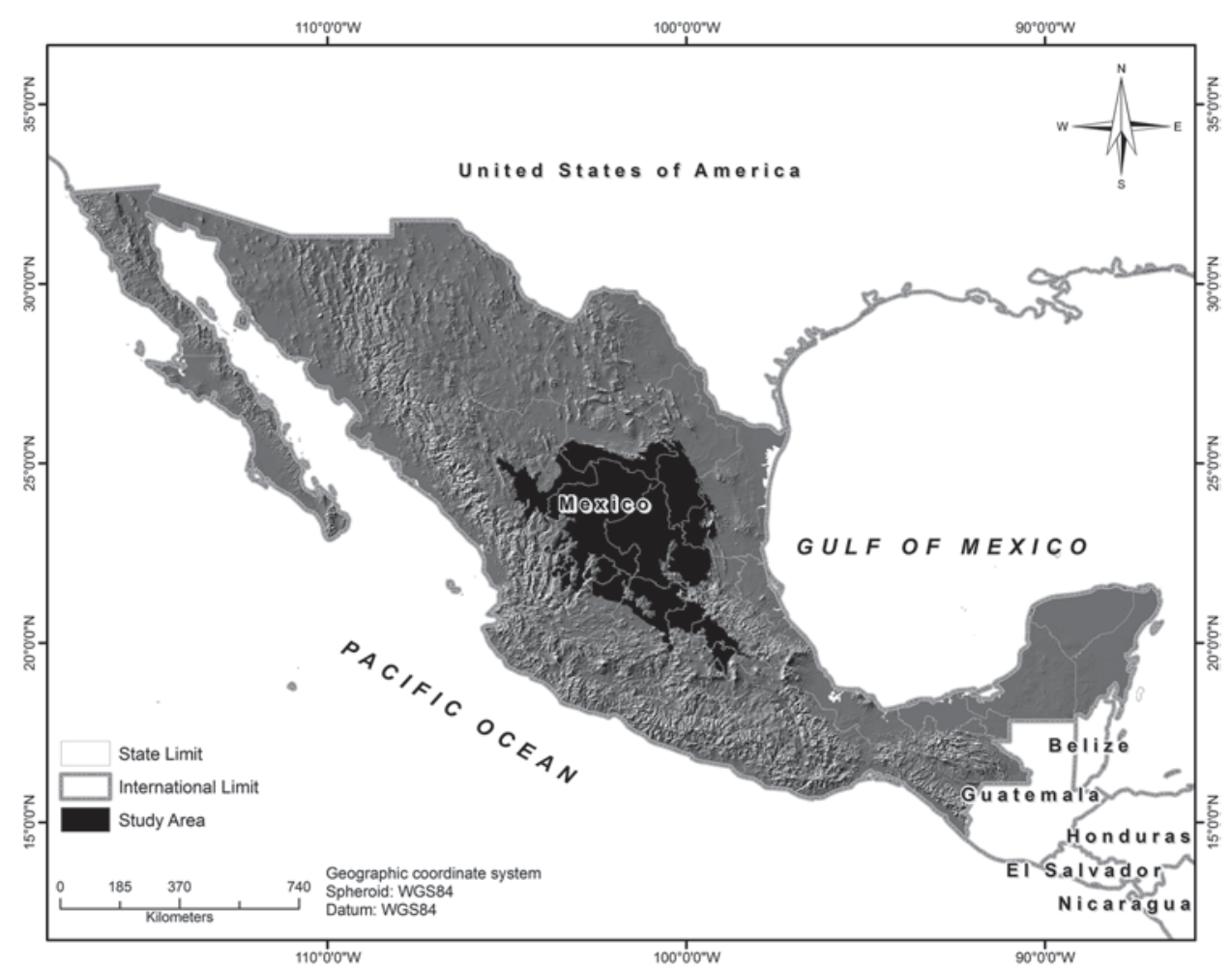

Figure 1. Location of the modelled area. The black region corresponds to the 'Meseta Central Matorral' (MCM), delimited as ' $\mathrm{M}^{\prime}$ according to Soberón and Nakamura (2009).

\section{Environmental predictors}

Climatic variables were computed using the Digital Climate Atlas of Mexico dataset for 1902-2011 (Centro de Ciencias de la Atmósfera 2014). Altitude corresponded to the $\mathrm{GTOPO}_{3}$ o Elevations Model, with a spatial resolution of $1 \mathrm{~km}^{2}$, and was used to derive slope and topographical ruggedness (EROS 2014). Vegetation types were obtained from the INEGI Series IV digital map of land use and vegetation, 2007-2010 (INEGI 2010b; spatial resolution, 1:250,000), while soil classification data were obtained from INEGI (2013; spatial resolution, $1 \mathrm{~km}^{2}$ ). Prior to compiling the environmental variables in Maxent, we converted all layers to the same geographic scale and cell size of $1 \mathrm{~km}^{2}$.

To reduce multicollinearity between climatic variables, we used Pearson's correlation to select variables $(r>0.70)$; predictors with the highest correlations to others, were selected. Through this procedure, we reduced the set of environmental variables from 24 to 11 (Table 1 ).

\section{Maxent inputs and validation of the model}

Preliminary models were run to determine the optimal options for settings. For the final model, we used a random sampling of $25 \%$ for model evaluation and $75 \%$ for training data. We ran 5,000 maximum iterations and used the linear-quadratic-hinge feature for the basic model and the linear-quadratic feature for the breeding model. All other features remained at default settings. All models were run with 100 replicates. Given that the traditional Area Under the Curve (AUC) value of the Receiver Operating Characteristic (ROC) is not appropriate for 
Table 1. Predictors and their download sources. Codes for bioclimatic predictors were obtained from Bioclim (WorldClim-Project 2016).

\begin{tabular}{|c|c|c|}
\hline Code & Predictor description & Source \\
\hline ВIOп & Annual mean temperature & http://atlasclimatico.unam.mx/atlas/kml/ \\
\hline $\mathrm{BIO}_{2}$ & Mean diurnal temperature & \\
\hline $\mathrm{BIO}_{3}$ & Isothermality & \\
\hline $\mathrm{BIO}_{4}$ & Temperature seasonality & \\
\hline $\mathrm{BIO}_{5}$ & Maximum temperature of the warmest month & \\
\hline $\mathrm{BIO6}$ & Minimum temperature of the coldest month & \\
\hline $\mathrm{BIO}_{7}$ & Temperature annual range & \\
\hline $\mathrm{BIO} 8$ & Mean temperature of wettest quarter & \\
\hline $\mathrm{BIO}_{9}$ & Mean temperature of driest quarter & \\
\hline BIOı́ & Mean temperature of warmest quarter & \\
\hline $\mathrm{BIO}_{11}$ & Mean temperature of coldest quarter & \\
\hline $\mathrm{BIO}_{12}$ & Annual precipitation & \\
\hline $\mathrm{BIO}_{13}$ & Precipitation of wettest month & \\
\hline $\mathrm{BIO}_{4}$ & Precipitation of driest month & \\
\hline BIO15 $_{15}$ & Precipitation seasonality & \\
\hline BIOı6 & Precipitation of wettest quarter & \\
\hline $\mathrm{BIO}_{17}$ & Precipitation of driest quarter & \\
\hline BIOı 8 & Precipitation of warmest quarter & \\
\hline BIO19 & Precipitation of coldest quarter & \\
\hline Slo & Slope & http://eros.usgs.gov/ \\
\hline $\mathrm{Al}$ & Altitude & \\
\hline $\operatorname{Tr}$ & Topographical ruggedness & \\
\hline St & Soil type & $\begin{array}{l}\text { http://www.inegi.org.mx/geo/contenidos/ } \\
\text { recnat/edafologia/default.aspx. }\end{array}$ \\
\hline Veg & Vegetation & $\begin{array}{l}\text { http://www.inegi.org.mx/geo/contenidos/ } \\
\text { recnat/usosuelo/Default.aspx }\end{array}$ \\
\hline
\end{tabular}

evaluation of performance of models with no absences (Phillips et al. 2006), we used the partial ROC test (Nayarani 2008) after Peterson et al. (2008). The values generated by traditional AUC calculations (probabilities from o to 1 ) were multiplied by 100 and rounded to the nearest integer. The resulting table of modified values fed the partial ROC analysis (CONABIO 2015). The results generated by the partial ROC analysis are expressed as the ratio of the modified AUC area to the area of null expectation, following Peterson et al. (2008). This procedure was applied to each model. We report both AUC and partial ROC values.

\section{Field survey}

From June to July 2013, we searched for the presence of Worthen's Sparrow in the predicted new potential distribution areas, based on the output map of the basic model (including all areas from low to high probability; Figure 2a). The fieldwork was undertaken by three teams comprising four people each: one in the states of Nuevo León and Coahuila; another in San Luis Potosí; and the third in Aguascalientes, Jalisco and Guanajuato. All censuses were conducted on the same days and at the same times. Surveys began in the morning by driving along all tracks and roads that traversed patches of vegetation and publicly accessible communal lands ('ejidos'), at a speed of $15 \mathrm{~km} / \mathrm{hr}$. When searching for and discovering new populations, we simultaneously counted individuals as follows. Once we saw the species or heard singing males, we stopped and got out of the vehicle. Each person in the team walked a line transect in different cardinal directions, counting singing males. The observers continued to walk in the same direction until no further individuals were seen or heard. When a male flew away (not included in the count), the observer 

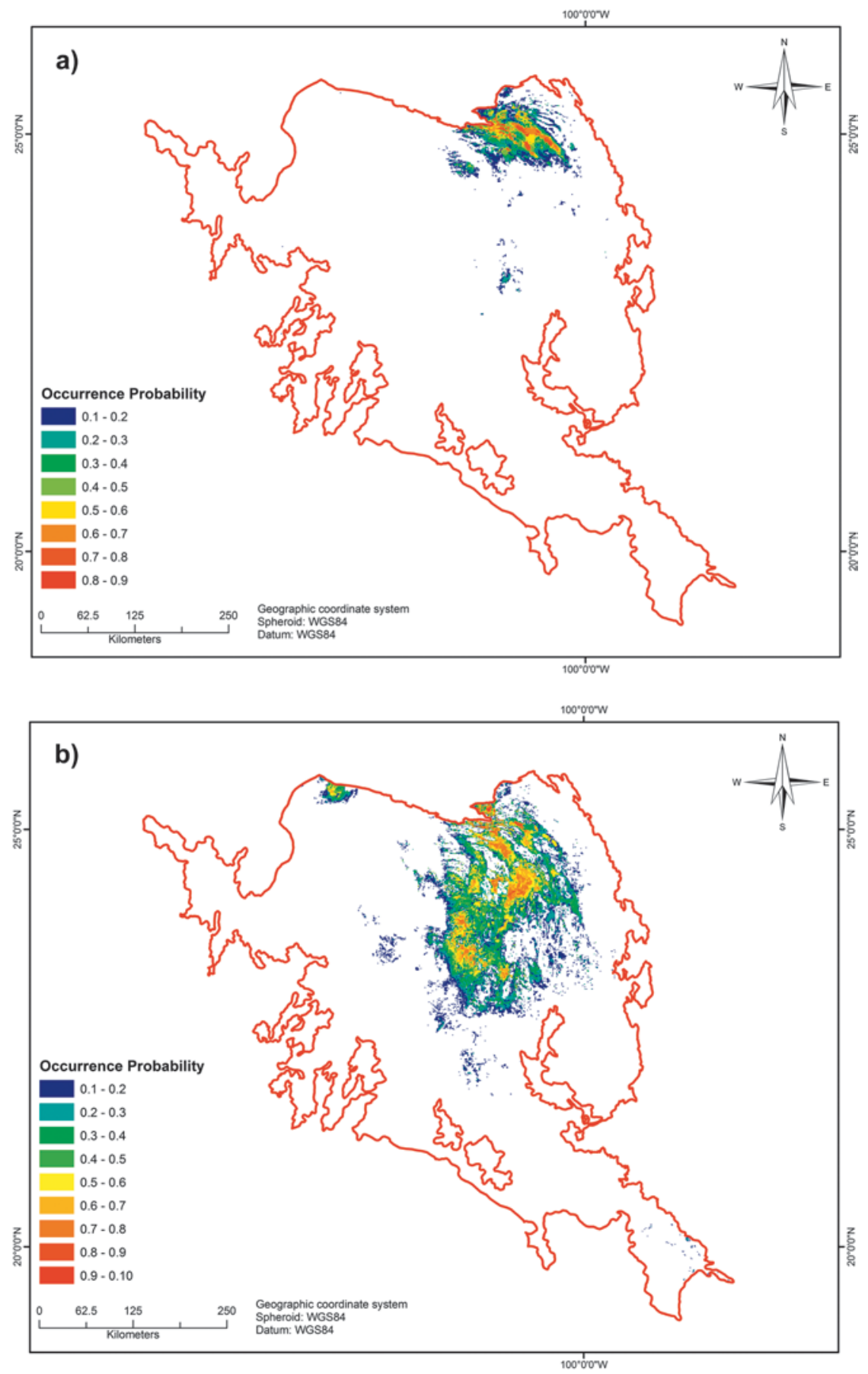

Figure 2. a) Potential range distribution of Worthen's Sparrow (AUC $=0.966, \mathrm{SD}=0.012$; partial $\mathrm{ROC}=1.8 \mathrm{O}, \mathrm{SD}=0.17)$ according to Scott-Morales and Vela Coiffier (2015). b) Potential breeding range $(\mathrm{AUC}=0.951, \mathrm{SD}=0.016$; partial $\mathrm{ROC}=1.57, \mathrm{SD}=0.37$ ) according to our breeding model. Colours represent the probability of bird presence. 
waited until the bird perched again or was lost and then continued the count. If a male flew into the transect, it was ignored. The coordinates of singing males (no further than $50 \mathrm{~m}$ distant) were recorded. The discreet behaviour of the observers ensured that males usually remained perched, even when they had stopped calling. Because of the open nature of the landscape (low creosote or tarbush with scattered Yucca sp.), we were certain that no males were counted twice, because they were easy to follow. After each count of singing males was finished, we returned to the starting point, searching for females and nests on the way. We searched for males each morning between o7hoo and 13 hoo and in the afternoon between 15 hoo and 19hoo. We undertook fieldwork in mid-summer across the species' potential geographic range, in order to be certain of finding calling males and confirming that the habitat was suitable for reproduction.

\section{Population estimation}

To estimate bird density we used the same line transects described above. The transects were of variable length and a total width of $100 \mathrm{~m}$. The areas of transects were calculated in hectares. Area of search density was calculated as the number of birds/io ha. The obtained value was rounded to the nearest unit. A definitive number of individuals was not registered in our census, as we were unable to access some areas.

\section{Extent of occurrence}

To estimate and update the extent of occurrence (EOO) of the species (IUCN 2012), we also determined geographical distributions using both historic (1980-2013) and updated (breeding season 2013) distribution data of the species, using the minimum convex polygon (MCP) method.

\section{Results}

The final potential geographic distributions of both the basic and breeding models (Figures 2a and b) generated high AUC and partial ROC test values, with AUCs of 0.966 (SD 0.012) and 0.951 (SD 0.016) and partial ROCs of 1.80 (SD 0.17) and 1.57 (SD 0.37), respectively, indicating that the performance of the models was adequate. The data collected in 2013 improved the potential breeding distribution of the species across the MCM, and confirmed that the current breeding habitat included vegetation other than tarbush-creosote bush. Other vegetative associations included in the breeding habitat of the species were halophytic grassland with scattered juniper Juniperus sp. and xeric scrubland, consisting of tarbush Flourensia cernua and creosote bush Larrea tridentata, along with scattered yucca Yucca filifera or mesquite Prosopis glandulosa; the highest densities occurred in the tarbush-creosote bush communities. In an altitudinal zone between 1,700 and 2,200 $\mathrm{m}$ asl, rainfall seasonality underpinned both models, indicating that the occurrence of species during the breeding season likely depends primarily on climatic conditions (Table 2).

The improvement in data quality and quantity of the breeding model resulted in a better projection of the species potential distribution model, and more reliable prediction of habitat availability relative to the basic model (probabilities of occurrence $\geq 0.6,1,725 \mathrm{~km}^{2}$ and $3,521 \mathrm{~km}^{2}$, respectively). We found to new small breeding populations further south of the historical geographic distribution, primarily in San Luis Potosí. Some locations in the west (Zacatecas state) also appear to be suitable for Worthen's Sparrow; however, although the species has recently been confirmed as present in that area (J. Cruzado pers. comm. 2015), we were prevented from undertaking fieldwork there because of security concerns. Similarly, we heard singing males in additional locations on private ranches during the fieldwork, but entrance to the proprieties was denied. 


\section{Extent of occurrence}

The EOO estimates from historical records were $87,800 \mathrm{~km}^{2}$ and $16,994 \mathrm{~km}^{2}$ for the breeding season in 2013 (Figure 3). The lack of records in the breeding season from the west and the southcentral portions of the study area (in the state of Zacatecas), where the species has been observed in the breeding season but not confirmed in this study (see above), led to an incomplete estimation of the breeding range, but did provide a current breeding range in the MCM for the first time. We did not find singing males in the states of Aguascalientes, Guanajuato, or Jalisco, as reported elsewhere in winter (aVerAves 2014).

\section{Population estimation}

We counted a total of 316 males, dispersed in small populations across the central part of the study area. The total distance travelled was 3,910 km. We walked 76 transects with a total length of $64 \mathrm{~km}$; I1, 14 and $39 \mathrm{~km}$ in Coahuila, Nuevo León and San Luis Potosí, respectively. The mean density of individuals for all states combined was $4 / 10$ ha (SD 2.05). In the separate states, estimated densities were $4 /$ Io ha (SD 2.26), 3/10 ha (SD 1.51) and 4/10 ha (SD 1.92) for Coahuila, Nuevo León and San Luis Potosí, respectively. We found birds breeding in small (2-20 males) and larger (> 80 males) groups; however, no solitary males were detected in our surveys. Although we cannot guarantee that all singing males located were breeding successfully and accompanied by females, we believe that the majority were, because we found nests and incubating females at all sites. If we assume a $1: 1$ sex ratio, our search area population estimate is 632 individuals. However, although only the northern area of the distribution range has previously been considered to contain the majority of the Worthen's Sparrow population, our results suggest otherwise; specifically, San Luis Potosí and potentially Zacatecas may contain almost $65 \%$ of the population (217 of the 316 records).

\section{Discussion}

Modelling of the data generated in 2013 confirm an expanded distribution and larger population of Worthen's Sparrow than previously proposed (Canales-Delgadillo et al. 2012; BirdLife

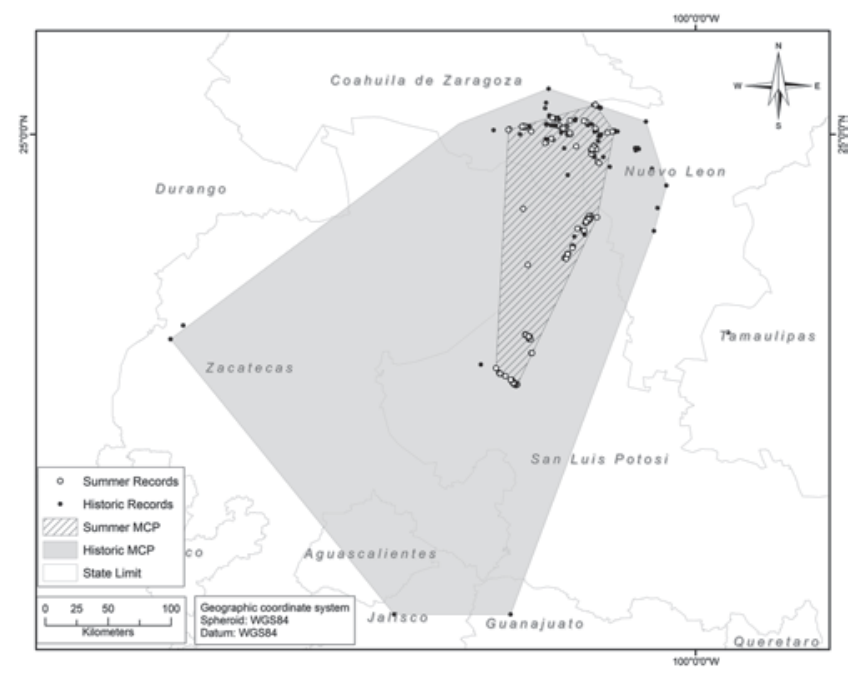

Figure 3. Estimated EOO of Worthen's Sparrow determined using data from 1980 to 2013 (historical records throughout the year; grey area), and generated using breeding data (summer 2013, hatched area). 
International 2016). Our estimation of the EOO (almost 17,00o km²) and AOO $\left(3,521 \mathrm{~km}^{2}\right)$, which constitute important criteria to determine conservation status (Endangered $\mathrm{B}_{1}$ and $\mathrm{B}_{2}$, IUCN 2012), considerably exceeded the Red List criteria specified by the IUCN of $\leq 5,000 \mathrm{~km}^{2}$ (EOO) and $500 \mathrm{~km}^{2}$ (AOO), and also exceed the previously reported EOO of $25 \mathrm{~km}^{2}$ for this species (BirdLife International 2016). Based on our re-evaluation of the status of Worthen's Sparrow using new data, we suggest a revision of the Red List status of the species from 'Endangered' to 'Vulnerable'.

Significant uncertainties exist about the actual historical range of Worthen's Sparrow, since historical records from Chihuahua and New Mexico have not been recently ratified. However, as the historical range of the species was considered to be $50,000 \mathrm{~km}^{2}$ (Wege et al. 1993), our estimation does reveal a reduction in range, relative to historical reports. While we were unable to assess the entire male population of Worthen's Sparrow, our revised data indicate a search area population of 632 individuals, which is substantially above the earlier estimate of 100 (BirdLife International 2016). Data on population size are not well documented, and some imprecise data were reported by Wege et al. (1993). These authors mentioned flocks from the states of Coahuila, Nuevo León, San Luis Potosí, Tamaulipas and Zacatecas with fluctuations in size from 20 to 120 . Only through long-term monitoring can we confirm whether the species is increasing in numbers in suitable habitats across the Mexican Plateau, or whether limited records and lack of observations have caused its geographic range and population size to be underestimated.

We were able to confirm that Worthen's Sparrow is an errant species, congregating in small groups in the breeding season and with other species in the non-breeding season, with a fragmented distribution. It changes breeding location in accordance with recent rainfall, mainly tending to avoid dry sites. Similar behaviour has been reported in other species, which display opportunistic breeding, usually in association with nomadism (Zann et al. 1995, Morton et al. 2011). Although the lack of significance of land cover in explaining the presence of Worthen's Sparrow is perhaps surprising (Table 2), the flexibility of the species makes it possible for individuals to breed in different types of vegetation (as noted in this study), while their high mobility facilitates their dispersal to sites that have received adequate rainfall to breed. Our observations in 2012 confirmed the absence of the majority of the population from the northern part of the study area, from where most known historical breeding records are derived (despite land cover). Larger breeding populations were found in San Luis Potosí, where rainfall had been higher. Rainfall is well known to stimulate reproduction in a range of passerines in arid regions (Leitner et al. 2003, Hau et al. 2004, Illera and Diaz 2006), and Worthen's Sparrow appears to follow a similar pattern, since seasonal precipitation was the most important predictor in our modelling. In an era of climate change, it will be important to determine

Table 2. Contribution of the predictors used for the basic and breeding models: predictors highlighted in bold provided the greatest contribution.

\begin{tabular}{llc}
\hline Predictor & \multicolumn{2}{l}{ Percentage of contribution } \\
\cline { 2 - 3 } & Basic model & Breeding model \\
\hline BIO15 & $\mathbf{3 1}$ & $\mathbf{5 2}$ \\
BIO14 $_{\text {BIO }}$ & $\mathbf{2 7}$ & 4 \\
Slo & $\mathbf{2 2}$ & 7 \\
Veg & 6 & $\mathbf{1 6}$ \\
$\mathrm{Al}$ & 6 & 5 \\
$\mathrm{BIO}_{1}$ & 4 & 3 \\
$\mathrm{BIO}_{2}$ & 2 & 3 \\
$\mathrm{BIO}_{12}$ & 2 & 5 \\
$\mathrm{St}_{\mathrm{BI}}$ & 0 & 3 \\
$\mathrm{BI}_{17}$ & 0 & 2 \\
\hline
\end{tabular}


whether frequent rainfall can modify the habitat of Worthen's Sparrow and improve breeding areas and food availability, contrary to published statements (BirdLife International 2004).

In recognition of the conservation status of Worthen's Sparrow and the need to develop appropriate conservation strategies, a long-term monitoring strategy is necessary to confirm the population size of the species and temporal-spatial fluctuations in population numbers and distribution from year to year. The priority for conservation should be to maintain the natural vegetation of the Meseta Central Matorral as a mosaic of ecosystems and as a critical habitat, not only for Worthen's Sparrow, but also for other vulnerable species such as the Mexican prairie dog Cynomys mexicanus, kit fox Vulpes macrotis and badger Taxidea taxus.

The improvement of the EOO and AOO through the implementation of field research and use of a species distribution model (SDM) demonstrates the effectiveness of combining these factors for conservation purposes. It is possible to overcome the shortfall in information, with minor time investment and efficient research in relevant areas. Using the limited information available as a baseline (basic model), we were able to focus our search in potentially fruitful areas to improve data quantity and quality. However, it is necessary to have relevant knowledge of the ecology of the species and general features of the habitat, to make effective use of the information generated by the SDM. Our study is not novel in its support for the efficacy of SDMs for improvement of species conservation (Thorn et al. 2009, Torres and Jayat 2010, Sousa-Silva et al. 2014; Syfert et al. 2014); however our findings highlight the contribution of SDMs to fieldwork and monitoring, as we have gathered crucial data relevant to conservation assessment of a threatened species.

\section{Acknowledgements}

The research was funded by CONACyT (157677), CONABIO (JMoo4) and PAICyT (CN974-10). We particularly thank A. G. Luna, A. Sanchez, J. J. Briones, L. Martinez, F. García, A. Guerrero, A. Martínez and M. Reyes for field assistance. C. Garza, A. Rowell and N. Reid made valuable comments on an early draft. We thank our anonymous referees for incisive feedback on a previous version of the manuscript.

\section{References}

AOU (1998) Check-list of North American birds. $7^{\text {th }}$ editon. Lawrence, KS: American Ornithologists' Union.

aVerAves (2014) http://ebird.org/ebird/ averaves/eBirdReports?cmd=Start

Behrstock, R. A., Sexton, C. W., Lasley, G. W., Eubanks, T. L. and Gee, J. P. (1997) First nesting records of Worthen sparrow (Spizella wortheni) for Nuevo León, México, with a habitat characterisation of the nest site and notes on ecology, voice, additional sightings and leg coloration. Cotinga 8: 27-33.

BirdLife International (2004) Climate change may make habitats become unsuitable in large parts of the range of Worthen's Sparrow. Presented as part of the BirdLife State of the world's birds website. Available from: http://www.birdlife.org/datazone/ sowb/casestudy/185. Checked: 26/05/2016
BirdLife International (2016) Spizella wortheni. The IUCN Red List of Threatened Species. Version 2014.3. www.iucnredlist. org. Downloaded on 20 November 2014.

Brave, N., Brave, V., Jiménez-Valverde, A., Lira-Noriega, A., Maher, S. P., Peterson, T. A, Soberón, K. and Villalobos, F. (2011) The crucial role of accessible area in ecological niche modelling and species distribution modelling. Ecol. Modell. 222: 1810-1919.

Canales del Castillo, R. (2010) Biología y genética de la conservación del gorrión amenazado y endémico del noreste de Spizella wortheni. $\mathrm{PhD}$ thesis, Universidad Autónoma de Nuevo León, Facultad de Ciencias Biológicas. Nuevo León, México.

Canales-Delgadillo, J. C., Scott-Morales, L. M., Niehuis, O. and Korb, J. (2010) Isolation and characterization of nine microsatellite 
loci in the endangered Worthen's sparrow (Spizella wortheni). Conserv. Genet. Resour. 2: 151-153.

Canales-Delgadillo, C., Scott-Morales, L. M. and Korb, J. (2012) The influence of habitat fragmentation on genetic diversity of a rare bird species that commonly faces environmental fluctuations. J. Avian Biol. 42: $168-176$.

Centro de Ciencias de la Atmosfera (2014) Digital climatic atlas of Mexico. México: Centro de Informática para las Ciencias Atmosféricas y Ambientales, UNIATMOS, UNAM.

CONABIO (Comisión Nacional de Biodiversidad) (2015) http://nicho.conabio.gob. $\mathrm{mx} /$ home/proposito-y-guia-del-usuario/ validacion-del-modelo

EROS (2014) Centre for NASA's Land Processes Distributed Active Archive Centre (LP DAAC). URL http://eros.usgs.gov.

ESRI (2009) ArcGis 9.3.1. Redlands, CA: Environmental Systems Research Institute. Hau, M., Wikelski, M., Gwinner, H. and Gwinner, E. (2004) Timing of reproduction in a Darwin's finch: temporal opportunism under spatial constraints. Oikos 106: 498-500.

Illera, J. C. and Díaz, M. (2006) Reproduction in an endemic bird of semiarid island: a foodmediated process. J. Avian Biol. 37: 447-456.

INEGI (2010a) Mapa digital de Estados del Marco Geoestadistico. México: Instituto Nacional de Estadística y Geografía. http://www.inegi. org.mx/geo/contenidos/geoestadistica/m_ geoestadistico_2010.aspx

INEGI (2010b) Mapa digital de Uso del suelo y vegetación. Escala 1:250,000. Serie IV, 2007. México: Instituto Nacional de Estadística y Geografía.

INEGI (2013) Recursos Naturales. Conjunto de datos vectorial edafológico escala 1:250 000 Serie II (Continuo Nacional). Downloaded on 20 September 2014. http://www.inegi. org.mx/geo/contenidos/recnat/edafologia/ default.aspx.

IUCN (2012) IUCN Red List Categories and Criteria: Version 3.1. Second edition. Gland, Switzerland and Cambridge, UK: IUCN. Available at: http://www.iucnredlist.org/ static/categories_criteria_3_I\#critical.

Leitner, S., van Hof, T. J. and Gahr, M. (2003) Flexible reproduction in wild canaries is independent of photoperiod. Gen. Compar. Endocrinol. 130: 102-108.

Morton, S. R., Stafford Smith, D. M., Dickman, C. R., Dunkerley, D. L., Friedel, M. H., McAllister, R. R. J., Reid, J. R. W., Roshier, D. A., Smith, M. A., Walsh, F. J., Wardle, G. M., Watson, I. W. and Westoby, M. (2011) A fresh framework for the ecology of arid Australia. J. Arid Environ. 75: 313-329.

Nayarani, B. (2008) Tool for Partial-ROC. ver. 1.o. Lawrence, KS: Biodiversity Institute.

Peterson, T. A., Papes, M. and Soberon, J. (2008) Rethinking receiver operating characteristic analysis applications in ecological niche modelling. Ecol. Model. 213: 63-72.

Phillips, S. J., Dudik, M. and Schapire, R. R. (2004) A Maximum entropy approach to species distribution modelling. Proc. Twenty-First Int. Conf. Machine Learning: 655-662.

Phillips, S. J., Anderson, R. P. and Schapire, R. E. (2006) Maximum entropy modelling of species geographic distribution. Ecol. Model. 190: 231-259.

Phillips, S. J., Dudik, M. and Schapire, R. E. (2010) Maxent software for habitat modelling, ver. 3.3.3e.

Sada, A. M. (1987) Location for finding Worthen's Sparrow (Spizella wortheni) in Nuevo León. MBA Bulletin Board I (87-3): 2.

Scott-Morales, L. M. and Vela-Coiffier, P. (2015) Modelos predictivos de distribución para Spizella wortheni, Cynomys mexicanus, Vulpes macrotis zinzeri y Taxidea taxus berlandieri. Linares, NL, Mexico: Universidad Autónoma de Nuevo León. Facultad de Ciencias Forestales. Informe final SNIBCONABIO, proyecto No. JMoo4. México D.F.

SEMARNAT (2010) Norma Oficial Mexicana NOM-059-SEMARNAT-2010. Diario Oficial de la Federación (DOF).

Soberón, J. and Nakamura, M. (2009) Niche and distribution areas: concepts, methods, and assumptions. Proc. Nat. Acad. Sci. USA 106: 19644-19650.

Soberón, J, and Peterson, T. (2005) Interpretation of models of fundamental ecological niches and species' distributional areas. Biodiversity Informatics 2: 1-10.

Sousa-Silva, R., Alves, P., Honrado, J. and Lomba, A. (2014) Improving the assessment 
and reporting on rare and endangered species through species distribution models. Global Ecol. Conserv. 2: 226-237.

Syfert, M. M., Joppa, L., Smith, M. J., Coomes, D. A., Bachman, S. P. and Brummitt, N. A. (2014) Using species distribution models to inform IUCN Red List assessment. Biol. Conserv. 177: 174-184.

Thorn, J. S., Nijman, V., Smith, D. and Nekaris, K. A. I. (2009) Ecological niche modelling as a technique for assessing threats and setting conservation priorities for Asian slow lorises (Primates: Nycticebus). Divers. Distrib. 15: 289-298.

Torres, R. and Jayat, P. (2010) Modelos predictivos de distribución de cuatro especies de mamíferos (cingulate, arqueodactyla y rodentia) del Chaco en Argentica. Mastoz. Neotrop. 17: 335-352.

Wege, D. C., Howell, S. N. G. and Sada, A. M. (1993) The distribution and status of Worthen's Sparrow Spizella wortheni: a review. Bird Conserv. Internatn. 3: 211-220.

Williams, J. N., Seo, C., Thorne, J., Nelson, J. K., Erwin, S., O'Brien, J. M. and WWF (2014) Meseta Central Matorral.Southern North America: Central Mexico. www. worldwildlife.org/ecoregions/na1307.

WorldClim-Project (2016) Global Climate Data. http://www.worldclim.org/bioclim

Zann, R. A., Morton, S. R., Jones, K. R. and Burley, N. T. (1995) The timing of breeding by zebra finches in relation to rainfall in central Australia. Emu 95: 208-222

\section{LAURA M. SCOTT-MORALES*, MAURICIO COTERA-CORREA}

Facultad de Ciencias Forestales, UANL, Carretera Nacional km 145, 67700 Linares, Nuevo León, Mexico.

\section{PATRICIA VELA-COIFFIER}

Instituto Tecnológico y de Estudios Superiores de Monterrey, Eugenio Garza Sada 2501, 64849 Monterrey, Mexico.

\section{MIRNA ALMEJO-RAMOS}

Centro Universitario de la Costa Sur, U de G. 151 Centro, 48900 Autlán de Navarro, Jalisco, Mexico.

\section{JULIO CANALES-DELGADILLO}

CONACyT-Instituto de Ciencias del Mar y Limnologia, Estacion El Carmen, UNAM, Carretera Carmen-Puerto Real km 9.5, 24157 Cd. del Carmen. Campeche, Mexico.

*Author for correspondence; e-mail: laura.scottmr@uanl.edu.mx

Received 18 October 2015; revision accepted 3 June 2017; Published online 7 August 2017 